\title{
Factors influencing the restoration of fluid and electrolyte balance after exercise in the heat
}

\author{
R J Maughan, J B Leiper, S M Shirreffs
}

\begin{abstract}
Summary
Maintenance of fluid balance is a major concern for all athletes competing in events held in hot climates. This paper reviews recent work relating to optimisation of fluid replacement after sweat loss induced by exercising in the heat. Data are taken from studies undertaken in our laboratory. Issues investigated were drink composition, volume consumed, effects of consuming food with a drink, effects of alcohol on rehydration effectiveness, voluntary intake of fluid, and considerations for women related to the menstrual cycle. The results are presented as a series of summaries of experiments, followed by a discussion of the implications. The focus of this review is urine output after ingestion of a drink; fluid excreted in urine counteracts rehydration. Also included are data on the restoration of plasma volume losses. Ingestion of large volumes of plain water will inhibit thirst and will also promote a diuretic response. If effective rehydration is to be maintained for some hours after fluid ingestion, drinks should contain moderately high levels of sodium (perhaps as much as $50-60$ $\mathrm{mmol} / \mathrm{l}$ ) and possibly also some potassium to replace losses in the sweat. To surmount ongoing obligatory urine losses, the volume consumed should be greater than the volume of sweat lost. Palatability of drinks is important in stimulating intake and ensuring adequate volume replacement. Where opportunities allow, the electrolytes required may be ingested as solid food consumed with a drink. There are no special concerns for women related to changes in hormone levels associated with the menstrual cycle. Ingestion of carbohydrate-electrolyte drinks in the post-exercise period restores exercise capacity more effectively than plain water. The effects on performance of an uncorrected fluid deficit should persuade all athletes to attempt to remain fully hydrated at all times, and the aim should be to start each bout of exercise in a fluid replete state. This will only be achieved if a volume of fluid in excess of the sweat loss is ingested together with sufficient electrolytes.
\end{abstract}

\section{Introduction}

Sustained hard exercise in a hot environment presents a greater challenge to the body's homoeostatic mechanisms than any other circumstance. The combination of a high rate of metabolic heat production and a restricted capacity for heat dissipation leads to hyperthermia, which may progress to heat illness; this will inevitably impair exercise performance, and may in extreme cases be fatal. ${ }^{1}$

The 1996 Olympic Games held in Atlanta in July and August were but one example of a major sporting event held in unfavourable climatic conditions; many others are scheduled for the near future. The combination of high temperature and high humidity has major implications for everyone attending; this includes spectators, officials, and team management as well as competitors. Performance in all outdoor endurance events, which we can define as those lasting longer than a total time of about 20-30 minutes, is generally reduced, and there seems to be no way of avoiding some impairment of performance. A recent study under laboratory conditions ${ }^{2}$ has shown that endurance time on a bicycle ergometer at an exercise intensity that could be sustained for 92 minutes at a temperature of $11^{\circ} \mathrm{C}$ was reduced to 83 minutes when the temperature was increased to $21^{\circ} \mathrm{C}$ and to 51 minutes when the temperature was increased to $30^{\circ} \mathrm{C}$; in Atlanta conditions, the reduction would be even greater. If the athlete is dehydrated before exercise begins, the reductions in performance observed in the heat are greatly magnified.

For those unaccustomed to living in the heat, the stress will be no different from that experienced by those who are accustomed to the heat, but the way in which the athletes deal with the conditions may be the largest factor influencing the impact of the climatic stress on their performance. The successful competitor will have prepared a coping strategy that includes acclimatisation, rehydration, and behavioural and psychological components. Aside from behavioural mechanisms to minimise or prevent overheating such as moving indoors to an air conditioned cool environment, the physiological mechanisms activated by the acclimation process include an earlier onset of sweating and an increased sweating rate. Sweating can be very effective in removing heat from the body, and substantial amounts of fluid are likely to be lost in this way by many individuals. The acclimation process results in an increased sweat loss and therefore increases, rather than decreases, the need for fluid replacement. The water lost must be replaced in order to 
maintain body water balance and allow the best possible athletic performance to be achieved. In addition, it is well established that dehydration removes the thermoregulatory advantage and improved exercise tolerance that result from acclimatisation. ${ }^{3}$

Although the physician and physiologist disapprove, it seems to be beneficial, at least in terms of performance, for athletes in weight category sports, including wrestlers, boxers, and weightlifters, to perform while in a dehydrated state; the disadvantage arising from competing with a body water deficit has been found by trial, error, and the experience of coach and athlete to be outweighed by the advantages of competing in a weight category below the athlete's natural weight. ${ }^{4}$ The advantage probably arises from biomechanical factors, including limb leverage advantages. However, the optimisation of rehydration after sweat loss induced to make weight at the time of the weigh-in may be of particular importance to performers in these sports. There are also many other athletes, including those who have to compete in more than one round of a competition on the same day or on successive days, for whom recovery and rehydration between events is of crucial importance.

The difficulty of achieving effective rehydration after thermal dehydration has long been recognised. Ingestion of water causes a prompt diuresis even when the individual is still hypohydrated, effectively preventing a return to euhydration. ${ }^{5}$ More recent studies have confirmed that plain water is not the best solution to be consumed after exercise to replace the water lost as sweat. ${ }^{67}$ These studies have highlighted the need for replacement of electrolytes as well as water, but have generally been non-systematic, with a number of variables changing simultaneously, leading to some difficulties in the interpretation of the results and in the formulation of recommendations for athletes. These reports have, however, also repeated earlier observations that voluntary fluid consumption generally stops short of the amount necessary to replace losses, leading to an involuntary dehydration. Levels of hypohydration equivalent to about $1 \%$ of body mass are sufficient to affect thermoregulatory responses to exercise; deficits of $2-3 \%$ of total body water, although sufficient to impair exercise performance, are not effective in initiating the drive to drink, and substantial fluid deficits (up to $5-10 \%$ of total body water) are well tolerated at rest by the healthy individual. ${ }^{3}$ If physical work is to be sustained, however, the need for adequate hydration becomes critical at these levels of hypohydration.

This review will describe some of our recent work concerning issues which must be considered if optimisation of fluid replacement after sweating induced by exercising in the heat is to be achieved. The aim of this series of investigations has been to complete a systematic investigation of some of the factors that influence restoration of fluid balance after exercise-induced dehydration. The factors that govern fluid replacement during exercise have been extensively investigated and are the subject of a number of comprehensive reviews ${ }^{8-11}$; these issues will not be discussed further here. We have focused on replacement after exercise in preparation for the next bout of exercise, be it training or competition. Our concerns deal with the composition of the fluid consumed, with particular regard to its electrolyte content, the volume of fluid consumed, the effects of consuming food together with a drink, the effects of consuming alcohol on rehydration effectiveness, voluntary intake of fluid after exercise, and any special considerations for female athletes in view of possible menstrual cycle effects on the rehydration effectiveness of beverages. Finally, there has been an initial investigation of the possible implications of the restoration of fluid and electrolyte balance on the ability to perform an exhausting exercise task. These results are presented as a series of summaries of individual experiments, followed by a short discussion of the implications for the athlete in training or competition.

\section{General outline of studies}

In all of these individual experiments, a moderate level of dehydration was induced by intermittent exercise in a hot (about $34^{\circ} \mathrm{C}$ ) humid (60-80\% relative humidity) environment. Subjects exercised until body mass had decreased by about $2 \%$ of the initial value; for a $70 \mathrm{~kg}$ subject, this corresponded to a sweat loss of about 1.4 litres. Beginning 30 minutes after the end of this exercise period, drinks of varying volume or composition were provided over a fixed time (60 minutes in most of the studies), and thereafter no further intake was allowed until the end of the study period. Measurements of urine volume and composition and of a variety of plasma variables (electrolyte concentrations, hormone levels, osmolality, and blood and plasma volume) were made throughout the study.

\section{Electrolyte content of drinks}

A study was undertaken to examine the effect of the sodium content of drinks on the rehydration process after exercise-induced dehydration equivalent to $1.9 \%$ of body mass of six fasted but euhydrated men. ${ }^{12}$ After dehydration they consumed drinks with sodium concentrations of $2,26,52$, and $100 \mathrm{mmol} / 1$ over a 30 minute period beginning 30 minutes after the end of exercise; the volume consumed was 1.5 times their mass loss by dehydration which amounted to about 2 litres in all trials. The entire volume of urine produced over the 5.5 hours after the end of the drinking period was collected and measured (no other food or drink was consumed after the rehydration period). The volume of urine produced was influenced by the quantity of sodium consumed, such that it was greatest when the 2 $\mathrm{mmol} / \mathrm{l}$ drink was consumed and least when the $100 \mathrm{mmol} / 1$ drink was consumed (fig 1), although the differences did not reach a level of significance between the 2 and 26 and between the 52 and $100 \mathrm{mmol} / \mathrm{l}$ drinks. Assuming a sweat sodium concentration of $50 \mathrm{mmol} / \mathrm{l}$ it is possible to calculate the whole body sodium balance at the end of the study period and 


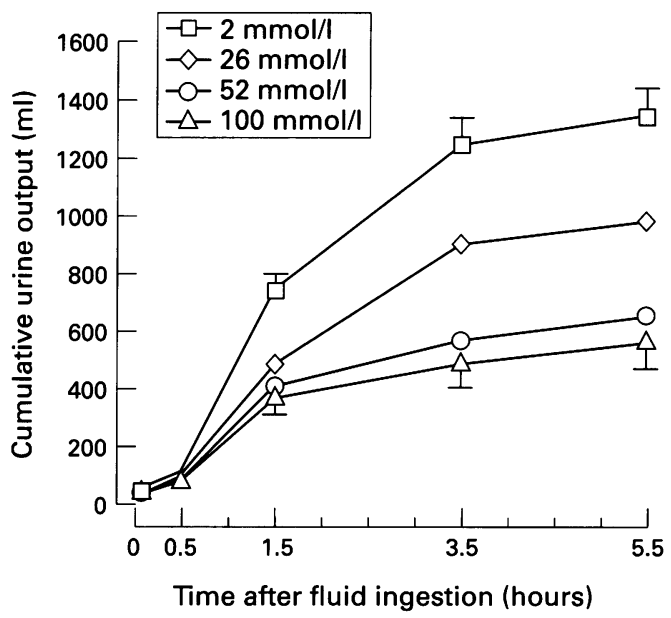

Figure 1 Cumulative urine output after rehydration over time after exercise-induced dehydration followed by ingestion of a fixed volume of glucose-electrolyte drinks with differing sodium content. Significant treatment effects were seen after the rehydration period. Redrawn from Maughan and Leiper. ${ }^{2}$

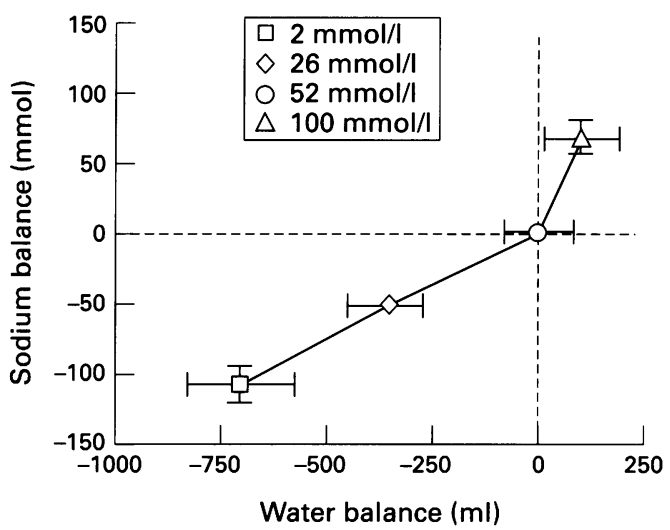

Figure 2 Relation between whole body water balance and sodium balance at 5.5 hours after the end of exercise-induced dehydration followed by ingestion of a fixed volume of fluid with different sodium concentration. $A$ sweat sodium concentration of $50 \mathrm{mmol} / \mathrm{l}$ was assumed. Redrawn from Maughan and Leiper. ${ }^{12}$

relate this to water balance, taking the preexercise values as the zero point (fig 2); this clearly shows that there is a strong relationship between the sodium content of the ingested fluid and its ability to restore water balance.

Blood samples were collected before and 30 minutes after the dehydration period (immediately before the test drink was consumed) and then at intervals until 5.5 hours after the end of the rehydration period. Plasma volume changes, calculated according to the formula of Dill and Costill, ${ }^{13}$ decreased with dehydration in all trials and increased after rehydration in all trials. Restoration of plasma volume occurred less rapidly with the $2 \mathrm{mmol} / \mathrm{l}$ beverage, in that 1.5 hours after the end of the fluid ingestion period, the increase in plasma volume was $6.8 \%$ in this trial, with increases of 12.4 and $12.0 \%$ with the 52 and $100 \mathrm{mmol} / 1$ drinks respectively. There was no difference in the change in plasma volume between trials 5.5 hours after the end of the rehydration period, but there was a tendency for it to be related to the quantity of sodium consumed, with the smallest increase with the $2 \mathrm{mmol} / \mathrm{l}$ beverage and the greatest increase with the $100 \mathrm{mmol} / 1$ beverage.

Sodium has an important function in assisting effective rehydration, largely as a consequence of its role as the major ion of the extracellular fluid. If sufficient sodium and water are ingested, some of the sodium remains in the vascular space, with the result that plasma osmolality and sodium concentration do not decline as may occur if plain water is ingested. As a result, the plasma levels of vasopressin and aldosterone are maintained, and an inappropriate diuresis, inappropriate because the body is still in net negative fluid balance, is prevented. Where ad libitum fluid intake is possible, maintaining the plasma osmolality and the circulating sodium concentration also plays a role in stimulating the drive to drink, and thus helps to ensure that an adequate volume is consumed.

Potassium is the major ion of the intracellular fluid, and it has been postulated that the inclusion of potassium in drinks consumed after sweat loss may aid rehydration by enhancing the retention of water in the intracellular space. ${ }^{14}$ In a study designed to investigate this, eight male volunteers were dehydrated by $2.1 \%$ of body mass by intermittent cycle ergometer exercise in the heat. ${ }^{15}$ Subjects ingested a glucose beverage (90 $\mathrm{mmol} / \mathrm{l})$, a sodium containing beverage $(\mathrm{NaCl}$ $60 \mathrm{mmol} / \mathrm{l}$ ), a potassium containing beverage ( $\mathrm{KCl} 25 \mathrm{mmol} / \mathrm{l}$ ), and a beverage consisting of the addition of all three over a 30 minute period beginning 45 minutes after the end of exercise. The drink volume consumed was equivalent to the volume of sweat lost and amounted to about 1.6 litres in all trials; no other food or drink was consumed during the study. The urine produced and excreted from the end of the rehydration period for the next six hours was again collected.

A smaller volume of urine was excreted after rehydration when the electrolyte containing beverages were ingested compared with the electrolyte free beverage (fig 3). An estimated plasma volume decrease of $4.4 \%$ was observed

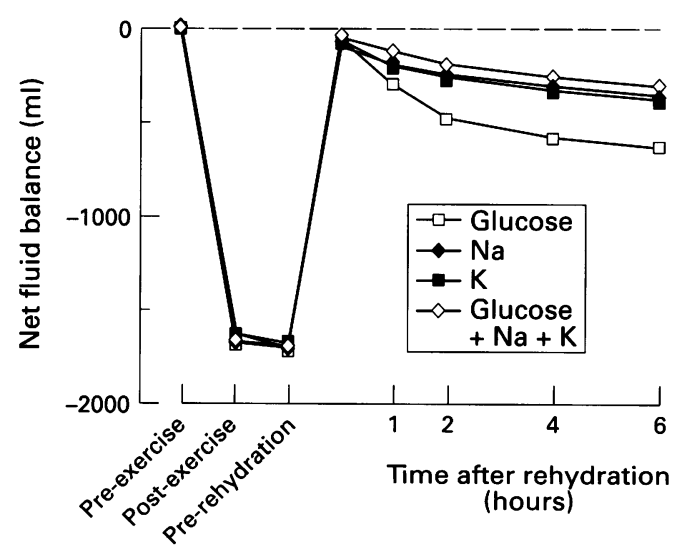

Figure 3 Changes in whole body fluid balance over time after exercise-induced dehydration followed by ingestion of drinks containing no electrolytes or containing sodium, potassium, or both sodium and potassium. Cumulative urine output was higher after ingestion of the electrolyte free drink than after ingestion of any of the other drinks, causing a rapid return to a negative fluid balance. Based on data from Maughan et al. ${ }^{\text {IS }}$ 


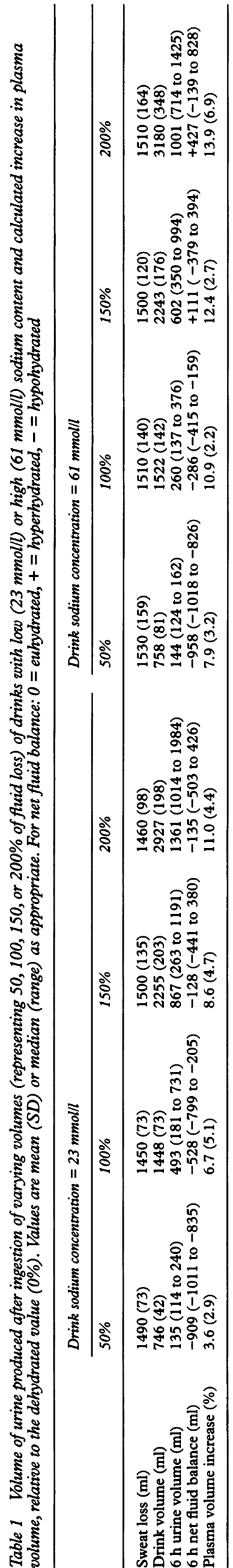

with dehydration over all trials. After drink ingestion, plasma volume increased in all trials, but the rate of recovery was slower when the $\mathrm{KCl}$ beverage was consumed. However, by the end of the study period, six hours after the end of the rehydration period, the increase was not different between trials and amounted to 7.5 (5.1) $\%$ for the glucose-electrolyte beverage, 9.7 (6.2)\% for $\mathrm{NaCl}, 7.8$ (5.1)\% for the $\mathrm{KCl}$ solution, and $7.9(2.0) \%$ for the beverage containing all three components (results are means (SD)). Although there were differences in the total amount of electrolyte replaced as well as differences in the type of electrolytes present in the drinks, there was no difference in the fraction of ingested fluid retained six hours after the drinks that contained electrolytes had been finished. It could be postulated, however, that as the beverage volume consumed was equivalent to the volume of sweat lost, subjects were dehydrated throughout the entire study, even after the drinking period. The volumes of urine excreted were close to basal levels, and significant further reductions in output may not have been possible when both sodium and potassium were ingested, over and above the reductions already induced when the sodium and potassium were ingested separately. This highlights the need to ensure that the volume of fluid consumed is sufficient not only to meet the fluid deficit incurred by sweating, but also to provide for ongoing urine and other losses.

Effects of the volume of fluid consumed As obligatory urine losses persist even in the dehydrated state, it is clear that any drink consumed after exercise-induced or thermal sweating must be consumed in a volume greater than the volume of sweat that has been lost. In order to investigate the influence of drink volume on rehydration effectiveness, 12 male volunteers performed intermittent exercise in the heat in order to induce a level of dehydration equivalent to a mean of $2.06 \%$ of their initial body mass. ${ }^{16}$ Over a 60 minute period beginning 30 minutes after the end of exercise, drink volumes equivalent to $50,100,150$, and $200 \%$ of the sweat loss were consumed. In addition, in order to investigate the possible interaction between beverage volume and its sodium content, six of the subjects consumed a relatively low sodium concentration drink $(23 \mathrm{mmol} / \mathrm{l})$, and six a moderately high sodium concentration drink $(61 \mathrm{mmol} / \mathrm{l})$. For six hours after the end of the drinking period, subjects consumed no other food or drink, and the entire volume of urine produced and excreted was collected and measured. When either the low or high sodium beverage was consumed, the urine volume produced was, not surprisingly, related to the beverage volume consumed, such that the smallest volumes were produced when $50 \%$ of the loss was consumed and the greatest when $200 \%$ of the loss was consumed (table 1 ).

As different drink volumes were consumed in each of the trials, a calculation of fluid balance status relative to the situation before the dehydration allows easier comparisons than a simple measure of the urine volume produced (table 1). With dehydration, individuals move 
Table 2 Volume of urine produced following drink ingestion. Also shown is the fluid volume consumed and the quantities of major electolytes ingested. Values are mean (SD) or median (range) as appropriate

\begin{tabular}{lcc}
\hline & Meal + water & Sports drink \\
\hline Fluid volume (ml) & $2076(371)$ & $2042(373)$ \\
Electrolytes ingested (mmol) & $63(11)$ & $43(8)$ \\
$\mathrm{Na}+$ & $21(3)$ & $7(3)$ \\
$\mathrm{K}+$ & $665(396$ to 1190$)$ & $934(550$ to 1403$)$ \\
$6 \mathrm{~h}$ urine volume (ml) & & \\
\hline
\end{tabular}

into negative fluid balance; by drinking they return towards a positive fluid balance status, and, only if the volume consumed is greater than the sweat loss, do they become positively hydrated. Urine output moves them towards and/or into a state of negative fluid balance status again. As shown in table 1 , subjects were significantly hypohydrated when they consumed a volume equivalent to only half their sweat loss irrespective of the drink composition. With a drink volume equivalent to that of the sweat loss, subjects were also hypohydrated at this time, but significantly less so when the higher sodium beverage had been consumed, confirming the effectiveness of sodium at promoting rehydration. When a drink volume double the sweat loss was consumed, subjects were still slightly hypohydrated six hours after drink ingestion when it had a low sodium concentration and indeed they were in a similar condition to when they drank the same beverage in a volume of only $150 \%$ of their sweat loss. With the high sodium drink, subjects had retained enough of the fluid to maintain them in a state of hyperhydration six hours after drink ingestion when they consumed either $150 \%$ or $200 \%$ of their sweat loss, and the excess retained would eventually be lost by urine production or by further sweat loss if the individual commenced exercise or moved to a warm environment. Calculated plasma volume changes indicated a decrease of about $5.3 \%$ with dehydration. At the end of the study period, the general pattern irrespective of which drink had been consumed, was for the increases in plasma volume to be a direct function of the volume of fluid consumed; in addition, the increase tended to be greater for those individuals who ingested the high sodium drink (table 1).

\section{Effects of solid food and fluid consumption}

In many situations it is not uncommon to consume solid food between exercise bouts, and indeed in most situations it probably should be encouraged. We undertook a further study in which eight volunteers (five men, three women) dehydrated by $2.1 \%$ of their body mass by exercising in the heat and then, over a 60 minute period starting 30 minutes after the end of exercise, consumed either a solid meal plus virtually electrolyte free flavoured water or

Table 3 Volume of drink consumed and fraction of fluid retained six hours after ingestion of drink of various alcoholic strengths $(0,1,2$, or $4 \%)$. Values are mean (SD)

\begin{tabular}{lcccccc}
\hline & $0 \%$ & $1 \%$ & & $2 \%$ & \multicolumn{2}{l}{$4 \%$} \\
\hline Drink volume (ml) & $2178(191)$ & 2240 & $(147)$ & 2275 & $(154)$ & 2155 \\
Fraction of fluid retained (\%) & $59.3(15.7)$ & $53.1(11.0)$ & $50.0(16.2)$ & $40.7(13.7)$ \\
\hline
\end{tabular}

a commercially available sports drink ${ }^{17}$; the volume of fluid contained within the meal plus water was the same as the volume of sports drink consumed. For six hours after the end of the eating and/or drinking period, the entire volume of urine produced and excreted was collected. The volume of urine produced after food plus fluid ingestion was significantly less than that when the drink alone was consumed (table 2). It was calculated that plasma volume decreased by $5.4 \%$ with dehydration over all trials. The plasma volume increased after rehydration in all trials, and there was no difference in the increase between the food plus fluid trial (11.7 (2.0)\%) and drink only trial (13.2 (4.2)\%) (means (SD)). The quantity of water consumed with both these rehydration methods was the same, but the meal had a greater electrolyte content (table 2), and it seems most likely that the greater efficacy of the meal plus water treatment in restoring whole body water balance was a consequence of the greater total cation content.

\section{Alcohol consumption}

Many people advise against the consumption of alcohol and caffeine containing beverages when fluid replacement is desired because they have been shown, at least in some circumstances, to act as diuretics. However, it is obvious that many people enjoy consuming these types of beverages in many circumstances. We therefore undertook a study to investigate the effect of consuming alcohol after exercise in the heat sufficient to induce dehydration equivalent to $2.01(0.06) \%$ of body mass. ${ }^{18} 19$ Over a 60 minute period beginning 30 minutes after the end of exercise, subjects consumed a volume equivalent to $150 \%$ of their mass loss of drinks containing $0,1,2$, or $4 \%$ alcohol; the drink composition was identical in all other respects. The volume of urine produced and excreted for the six hours after drink ingestion was measured and was found to be related to the quantity of alcohol consumed, with a larger volume the more alcohol that was consumed (table 3). However, despite the definite tendency for the urinary output to increase with increasing alcohol, only with the $4 \%$ beverage did the increased value approach significance. The calculated decrease in plasma volume with dehydration was about $7.6 \%$ across all trials. With rehydration the plasma volume increased, but the rate of increase seemed to be related to the quantity of alcohol consumed; at the end of the study period, the increase in plasma volume relative to the dehydrated value was 8.1 (3.2)\% with $0 \%$ alcohol, 7.4 (2.7)\% with $1 \%, 6.0$ (3.4)\% with $2 \%$, and 5.3 (3.4)\% with $4 \%$ (all results means (SD)).

\section{Voluntary beverage consumption}

We have already demonstrated and discussed the need for drinking more than the sweat volume lost to have a chance of rehydrating effectively. However, in practice it is left to the discretion of an individual how much they consume and what they choose to drink. In a study to examine the effect of palatability, together with the solute content of beverages in 
Table 4 Volume of drink consumed and net fluid balance four hours after rehydration. Values are mean (SD). For net fluid balance: $0=$ euhydrated, $+=$ hyperhydrated, $-=$ hypohydrated

\begin{tabular}{|c|c|c|c|c|}
\hline & $\begin{array}{l}\text { Glucose } 90 \mathrm{mmol} / \mathrm{l}+ \\
\text { sodium } 60 \mathrm{mmol} / \mathrm{l}+ \\
\text { potassium } 24 \mathrm{mmoll}\end{array}$ & Aerated water & $\begin{array}{l}\text { Sports drink (sodium } \\
24 \text { mmolll }+ \\
\text { potassium } 4 \text { mmolll) }\end{array}$ & $\begin{array}{l}\text { Orange/lemonade } \\
\text { (sodium } 2 \text { mmolllt } \\
\text { potassium } 24 \text { mmolll) }\end{array}$ \\
\hline $\begin{array}{l}\text { Drink volume (ml) } \\
4 \mathrm{~h} \text { net fluid balance (ml) }\end{array}$ & $\begin{array}{l}1796(758) \\
-123(615)\end{array}$ & $\begin{array}{l}1750(560) \\
-474(333)\end{array}$ & $\begin{array}{l}2492(661) \\
-135(358)\end{array}$ & $\begin{array}{r}2488(233) \\
45(238)\end{array}$ \\
\hline
\end{tabular}

promoting rehydration after sweat loss, eight men exercised in the heat to lose $2.1 \%$ of their mass. ${ }^{20}$ Over a two hour period after exercise, subjects were allowed to drink ad libitum; the drinks they received, each on a separate occasion, were a glucose-electrolyte beverage, aerated water, a commercial sports drink, and an orange juice/lemonade mixture. Subjects drank a greater volume of the sports drink and orange juice/lemonade mixture, the taste of which was perceived as being more pleasant (table 4). As different volumes of drinks were consumed, a calculation of fluid balance status relative to the situation before the dehydration allows easiest comparisons; with dehydration, individuals move into a negative fluid balance status, and by drinking they move towards a positive fluid balance status, and, only if the volume consumed is greater than the sweat loss, do they become positively hydrated, and urine production and excretion moves them towards and/or into the negative fluid balance status again. By consuming a greater volume, individuals give themselves a better chance of effectively rehydrating, and therefore the palatability of drinks, together with their composition, should be considered when free choice is given to individuals, as indeed occurs in most situations.

\section{Menstrual cycle effects: concerns for female athletes}

Almost all previous investigations into rehydration after exercise, as with so much human physiology, have been concerned exclusively with men. This is in part a consequence of the possibility that the steroid hormones, which are subject to cyclical variation in women, may have an influence on fluid balance, and the wish to avoid this confounding factor. We therefore undertook a specific study to establish whether or not there is an acute effect of these hormones on fluid balance in the few hours after exercise-induced sweat loss. ${ }^{21}$ Five women, each with a regular menstrual cycle, exercised in the heat to dehydrate themselves by $1.8 \%$ of their body mass. They did this at three different stages of their menstrual cycle (two days before, five and 19 days after the onset of menses), and, over a 60 minute period beginning 30 minutes after the end of exercise, they consumed the same quantity of the same beverage on each occasion; the volume con-

Table 5 Volume of urine produced after drink ingestion at various stages of the menstrual cycle. Also shown is the volume of drink consumed. Values are mean (SD) or median (range) as appropriate

\begin{tabular}{llll}
\hline & $\begin{array}{l}\text { 2 days before the } \\
\text { onset of menses }\end{array}$ & $\begin{array}{c}5 \text { days after the } \\
\text { onset of menses }\end{array}$ & $\begin{array}{l}19 \text { days after the } \\
\text { onset of menses }\end{array}$ \\
\hline Drink volume (ml) & $1662(195)$ & $1550(172)$ & $1392(241)$ \\
$6 \mathrm{~h}$ urine volume $(\mathrm{ml})$ & $714(469$ to 750$)$ & $476(433$ to 639$)$ & $534(195$ to 852$)$ \\
\hline
\end{tabular}

sumed was $150 \%$ of the mass loss and the drink, a commercially available sports drink, was the same in all trials. For six hours after the end of the rehydration period, the entire volume of urine excreted was collected and measured. There was no difference in the volume of urine produced (table 5), and hence in the volume of the ingested fluid that was retained at the different stages of the menstrual cycle. These results suggest that the acute replacement of volume losses incurred by sweat loss due to exercising in the heat are not affected by the normal regular menstrual cycle. Therefore women seem not to be disadvantaged when rapid and complete restoration of exercise-induced sweat loss is required.

\section{Performance effects}

The studies described above have used restoration of fluid balance as an index of recovery after exercise-induced dehydration, but many other factors are involved in the restoration of exercise capacity. To investigate some of the factors that influence recovery of performance capacity, a further experiment was undertaken; the study design was similar to that used previously, but subjects performed a standardised exercise test four hours after the end of the rehydration period. Rehydration was achieved by administration of plain water, a flavoured placebo, or a drink containing carbohydrate $(68 \mathrm{~g} / \mathrm{l})$ and electrolytes $(25 \mathrm{mmol} / \mathrm{l}$ sodium, 4 $\mathrm{mmol} / 1$ potassium) in a volume equal to 1.5 times the sweat loss of about $2 \%$ of body mass. The performance test consisted of an incremental cycling exercise test continued to the point of exhaustion.

The glucose-electrolyte test drink had an electrolyte content similar to that of most commercial sports drinks, and there was a tendency $(P=0.073)$ for the cumulative urine output over the four hour recovery period to be less in this trial (1162 (816-1429) ml; median (range)) than in the placebo (1470 (12281667) $\mathrm{ml}$ ) or water (1395 (954-1555) $\mathrm{ml}$ ) trials. This is consistent with the results of the previous trials, and confirms that this low level of electrolytes will give a small increase in the volume of fluid retained over this time scale.

All subjects recorded their best exercise performance, measured as the time to fatigue, on the carbohydrate-electrolyte trial, with a mean (SD) exercise time of 18.00 (2.43) minutes, compared with 16.42 (2.15) minutes after consuming the plain water and 17.00 (1.76) minutes in the placebo trial. These results suggest that there is a benefit from the addition of electrolytes and glucose to drinks ingested after exercise, but cannot distinguish between the various possible mechanisms that might be involved. It is, however, worth noting that there 
were no differences in the blood glucose concentration at any time between trials in spite of the ingestion of a substantial amount of carbohydrate on one of the trials. There is clearly a need for more systematic studies to resolve the outstanding questions.

\section{Discussion and conclusions}

Rapid and complete restoration of fluid balance after exercise is an important part of the recovery process, and becomes even more important in hot humid conditions. The choice of drink to be consumed after exercise may and indeed should be different depending on the individual and their particular circumstances. Replacement of substrate in addition to water and electrolyte losses may be of concern in the post-exercise period in preparation for a further bout of exercise. In terms of sustaining life, substrate (muscle and liver glycogen) depletion is unlikely to have an adverse effect in an otherwise healthy individual, but water depletion, if not reversed, may have serious consequences. Moderate levels of dehydration (2-3\% reductions in body mass) will impair performance, and when an Olympic medal is at stake, it might be wise to assume that even very low levels of dehydration may have a negative impact on performance; it is certainly the case that hypohydration of only $1 \%$ of body mass has a measurable effect on the thermoregulatory response to exercise. ${ }^{3}$ Severe dehydration (losses of more than about $6-\mathbf{7 \%}$ of body mass) can result in a life threatening situation, and this scenario is rendered more likely when the ambient temperature is high. ${ }^{1}$ Such extremes of water depletion should not occur in any athlete in the case of sports competition if a conscious effort is made to ensure adequate fluid replacement. However, even if the health concerns are ignored, the effects on performance of a fluid decrement should be enough to persuade all individuals to attempt to remain fully hydrated at all times, and particularly to ensure that they begin each bout of exercise in a water replete state.

Team doctors, coaches, and athletes must be aware of the factors that influence rehydration and of the electrolyte content of the available drinks. The amount of electrolytes lost in sweat is highly variable between individuals, and, although the optimum drink may be achieved by matching electrolyte loss with equal quantities from the drink, this is virtually impossible in a practical situation. Sweat composition varies considerably between individuals, but also varies with time during exercise and will be further influenced by the state of acclimation..$^{22}$ However, a moderate excess of salt intake would appear to be beneficial as far as hydration status is concerned without any detrimental effects on health provided that fluid intake is in excess of sweat loss and that renal function is not impaired. Concerns over the possible adverse effects of a high salt intake have led some athletes to restrict dietary salt intake. $^{23}$ For the athletes with large sweat losses, sodium loss will be correspondingly high; loss of 5 litres of sweat with a sodium content of $50 \mathrm{mmol} / 1$ requires ingestion of almost $15 \mathrm{~g}$ of sodium chloride to restore balance. This amount of sweat can easily be lost in 2-3 hours of hard training or match practice in hot humid conditions. Although the diet will make a major contribution to replacement, normal daily salt intake from food is only about 6-8 $\mathrm{g}$ for the UK population, about half of whom rarely or never add salt to food at the table. ${ }^{24}$ There is clearly a high risk of salt deficit when losses are high, unless a conscious effort is made to increase intake.

It is clear from the results described above, as well as those of many other studies, that rehydration after exercise can only be achieved if sweat electrolyte losses as well as water are replaced. The oral rehydration solution recommended by the World Health Organisation for the treatment of acute diarrhoea has a sodium content of $60-90 \mathrm{mmol} / \mathrm{l}$, reflecting the high sodium losses that may occur in some types of diarrhoea. ${ }^{25}$ In contrast, the sodium content of most of the major commercial sports drinks is in the range $10-25 \mathrm{mmol} / \mathrm{l}^{22}$ and is even lower in some products that are marketed as sports drinks. Most commonly consumed soft drinks contain virtually no sodium and these drinks are therefore unsuitable when the need for rehydration is crucial. The problem with a high sodium concentration in beverages is that it may exert a negative effect on taste, resulting in reduced consumption. It is equally clear, however, that drinks with a low sodium content are ineffective, and they will also reduce the stimulus to drink. ${ }^{26}$

It can generally be concluded that in order to achieve effective rehydration after exercise in the heat or heat exposure sufficient to cause sweat loss, the rehydration beverage should contain moderately high levels of sodium (at least $50 \mathrm{mmol} / \mathrm{l}$ ), plus possibly some potassium; a source of substrate is not necessary for rehydration, although a small amount of carbohydrate $(<2 \%)$ may improve the rate of intestinal uptake of sodium and water. The volume of beverage consumed should be greater than the volume of sweat lost in order to make provision for the ongoing obligatory urine losses. Therefore the palatability of the beverage is of importance; many individuals may lose substantial amounts of sweat and will therefore have to consume large amounts of fluid to replace them, and this is more likely to be achieved if the taste is perceived as being pleasant. Although we have shown that water alone is adequate for rehydration purposes when food that replaces the electrolytes lost in sweat is also consumed, there are many situations where intake of solid food is avoided. This is particularly true in weight category sports where the interval between the weigh-in and competition is short, but is also the case in events where only a few hours intervene between succeeding rounds of the competition.

The above studies were carried out in a systematic way and did not attempt to replicate real life situations where many other factors will intervene. After the exercise in the heat, individuals were removed to a relatively cool indoor environment and undertook no further exercise. For athletes living in training camps 
or in the village at major championship events where the outside environment is hot for the majority of most days, it is highly likely that they will be unable to avoid some exposure to a thermally stressful environment. Team support staff, officials, and spectators will also be at risk. All must be aware of the need to maintain fluid balance and should consider rehydration after passive heat exposure as well as after exercise. Indicators such as a reduction in urine output and failure to maintain body mass are more reliable measures of dehydration than the feeling of thirst.

SS was supported by a student research award from the Gatorade Sports Science Institute for the study of menstrual cycle effects on rehydration. We would like to thank Belinda Gooding of Masterfoods, UK, for the provision of Uncle Ben's rice and chili sauce used in the food plus fluid intake study. We would also like to thank Bass Brewers Ltd for the provision of drinks used in the alcohol study.

1 Sutton JR. Clinical implications of fluid imbalance. In: Gisolfi CV, Lamb DR, eds. Perspectives in exercise science and sports science, Vol 3. Fluid homeostasis during exercise. Carmel: Benchmark Press, 1990: 425-5

2 Galloway SDR, Shirreffs SM, Leiper JB, Maughan RJ Exercise in the heat: factors limiting exercise capacity and methods for improving heat tolerance. Sports, Exercise and Injury 1997;3:19-24.

3 Sawka MN, Pandolf KB. Effects of body water loss on physiological function and exercise performance. In Gisolf CV, Lamb DR, eds. Fluid homeostasis during exercise. Carmel: Benchmark Press, 1990:1-38.

4 Horswill CA. Physiology and nutrition for wrestling. In: Lamb DR, Knuttgen HG, Murray R, et al, eds. Perspectives in exercise science and sports science. Vol 7. Physiology and nutrition for competitive sport. Carmel: Cooper, 1994:13180.

5 Costill DL, Sparks KE. Rapid fluid replacement following thermal dehydration. $\mathcal{F}$ Appl Physiol 1973;34:299-303.

6 Gonzáles-Alonso J, Heaps CL, Coyle EF. Rehydration after exercise with common beverages and water. Int $\mathcal{f}$ Sports Med 1992;13:399-406.

7 Nielsen B, Sjogaard G, Uglevig J, Knudsen B, Dohlmann B. Fluid balance in exercise dehydration and rehydration with different glucose-electrolyte drinks. Eur $\mathfrak{f}$ Appl Physio 1986;55:318-25.

8 Coyle EF, Coggan AR. Effectiveness of carbohydrate feeding in delaying fatigue during prolonged exercise. Sports Med 1984;1:446-58.

9 Lamb DR, Brodowicz GR. Optimal use of fluids of varying formulations to minimise exercise-induced disturbances in homeostasis. Sports Med 1986;3:247-74.

10 Maughan RJ. Carbohydrate-electrolyte solutions during prolonged exercise. In: Lamb DR, Williams MH, eds. Perspectives in excrcise science and sports science. Volume 4. Epectives in exercise science and sports science. Volume 4. Brgogenics: the enhancement of

11 Murray $R$. The effects of consuming carbohydrateelectrolyte beverages on gastric emptying and fluid absorption during and following exercise. Sports Med 1987;4:32251.

12 Maughan RJ, Leiper JB. Sodium intake and post-exercise rehydration in man. Eur f Appl Physiol 1995;71:311-19.

13 Dill DB, Costill DL. Calculation of percentage changes in volumes of blood, plasma, and red cells in dehydration. $\mathcal{F}$ Appl Physiol 1974;37:247-48.

14 Nadel ER, Mack GW, Nose H. Influence of fluid replacement beverages on body fluid homeostasis during exercise and recovery. In: Gisolfi CV, Lamb DR eds. Perspectives in exercise science and sports medicine. Volume 3 . Fluid homeostasis during exercise. Carmel: Benchmark Press, 1990:181-205.

15 Maughan RJ, Owen JH, Shirreffs SM, Leiper JB. Postexercise rehydration in man: effects of electrolyte addition exercise rehydration in man: effects of electrolyte addit

16 Shirreffs SM, Taylor AJ, Leiper JB, Maughan RJ. Postexercise rehydration in man: effects of volume consumed and sodium content of ingested fluids. Med Sci Sports Exerc 1996; 28:1260-71.

17 Maughan RJ, Leiper JB, Shirreffs SM. Restoration of fluid balance after exercise-induced dehydration: effects of food and fluid intake. Eur $\mathcal{F}$ Appl Physiol 1996;73:317-25. 18 Shirreffs SM, Maughan RJ. The effect of alcohol consumption in man. $\mathcal{F}$ Physiol (Lond) 1995;489:33P-34P.

19 Shirreffs SM, Maughan RJ. The effect of alcohol consumption on the restoration of blood and plasma volume following exercise-induced dehydration in man. $\mathcal{F}$ Physiol (Lond) 1996;491:64P-65P.

20 Maughan RJ, Leiper JB. Post-exercise rehydration in man effects of voluntary intake of four different beverages. Med Sci Sports Exerc 1993;25:12S.

21 Maughan RJ, McArthur M, Shirreffs SM. Influence of menstrual status on fluid replacement after exercise-
induced dehydration in healthy young women. $B r \mathcal{J}$ Sports induced dehydratio

22 Maughan RJ. Fluid and electrolyte loss and replacement in exercise. In: Harries M, Williams C, Stanish WD, Michel LJ, eds. Oxford textbook of sports medicine. New York: Oxford University Press, 1994:82-93.

23 Bergeron MF. Heat cramps during tennis: a case report. In f Sport Nutr 1996;6:62-8.

24 Gregory J, Foster K, Tyler H, Wiseman M. The dietary and nutritional survey of British adults. London: HMSO, 1990.

25 Walker-Smith JA. Recommendations for oral rehydration solutions for use in the treatment of diarrhoeal disease in European children. 7 Pediatr Gastroenterol Nutr 1992;14: 113-15.

26 Nose H, Mack GW, Shi X, Nadel ER. Role of osmolality and plasma volume during rehydration in humans. $\mathcal{f} A p p l$ Physiol 1988;65:325-31 